University of Nebraska - Lincoln

DigitalCommons@University of Nebraska - Lincoln

Anthony Zera Publications

Papers in the Biological Sciences

$4-2018$

\title{
Diurnal and developmental differences in gene expression between adult dispersing and flightless morphs of the wing polymorphic cricket, Gryllus firmus: Implications for life-history evolution
}

Anthony J.Zera

University of Nebraska - Lincoln, azera1@unl.edu

Neetha Nanoth Vellichirammal

University of Nebraska-Lincoln, neetha@unl.edu

Jennifer A. Brisson

University of Rochester, jennifer.brisson@rochester.edu

Follow this and additional works at: https://digitalcommons.unl.edu/bioscizera

Part of the Developmental Biology Commons, Entomology Commons, and the Other Biochemistry, Biophysics, and Structural Biology Commons

Zera, Anthony J.; Vellichirammal, Neetha Nanoth; and Brisson, Jennifer A., "Diurnal and developmental differences in gene expression between adult dispersing and flightless morphs of the wing polymorphic cricket, Gryllus firmus: Implications for life-history evolution" (2018). Anthony Zera Publications. 41.

https://digitalcommons.unl.edu/bioscizera/41

This Article is brought to you for free and open access by the Papers in the Biological Sciences at DigitalCommons@University of Nebraska - Lincoln. It has been accepted for inclusion in Anthony Zera Publications by an authorized administrator of DigitalCommons@University of Nebraska - Lincoln. 


\title{
Diurnal and developmental differences in gene expression between adult dispersing and flightless morphs of the wing polymorphic cricket, Gryllus firmus: Implications for life-history evolution
}

\author{
Anthony J. Zera, ${ }^{1}$ Neetha Nanoth Vellichirammal, ${ }^{2}$ \\ \& Jennifer A. Brisson ${ }^{3}$ \\ 1 School of Biological Sciences, University of Nebraska-Lincoln, NE 68588 \\ 2 Department of Entomology, University of Nebraska-Lincoln, NE 68583 \\ 3 Department of Biology, University of Rochester, Rochester, NY 14627
}

Corresponding author - A.J. Zera, email azera1@unl.edu

\begin{abstract}
The functional basis of life history adaptation is a key topic of research in life history evolution. Studies of wing polymorphism in the cricket Gryllus firmus have played a prominent role in this field. However, prior in-depth investigations of morph specialization have primarily focused on a single hormone, juvenile hormone, and a single aspect of intermediary metabolism, the fatty-acid biosynthetic component of lipid metabolism. Moreover, the role of diurnal variation in life history adaptation in G. firmus has been understudied, as is the case for organisms in general. Here, we identify genes whose expression differs consistently between the morphs independent of time-of-day during early adulthood, as well as genes that exhibit a strong pattern of morph-specific diurnal expression. We find strong, consistent, morph-specific differences in the expression of genes involved in endocrine regulation, carbohydrate and lipid metabolism, and immunity - in particular, in the expression of an insulin-like-peptide precursor gene and genes involved in triglyceride production. We also find that the flight-capable morph exhibited a substantially greater number of genes exhibiting diurnal change in gene expression compared with the flightless morph, correlated with the greater circadian change in the hemolymph juvenile titer in the dispersing morph. In fact, diurnal differences
\end{abstract}


in expression within the dispersing morph at different times of the day were significantly greater in magnitude than differences between dispersing and flightless morphs at the same time-of-day. These results provide important baseline information regarding the potential role of variable gene expression on life history specialization in morphs of G. firmus, and the first information on genetically-variable, diurnal change in gene expression, associated with a key life history polymorphism. These results also suggest the existence of prominent morph-specific circadian differences in gene expression in G. firmus, possibly caused by the morph-specific circadian rhythm in the juvenile hormone titer.

Keywords: Wing polymorphism, Morph-specific gene expression, Circadian rhythm, Life history, Insulin-like peptide, Juvenile hormone

\section{Introduction}

For decades, the functional (physiological, biochemical, molecular) basis of life history adaptation has been a central topic of research on life history evolution (Stearns, 1992; Zera and Harshman, 2001; Harshman and Zera, 2007; Flatt and Heyland, 2011). However, despite considerable study, only the basic outlines are known for many key aspects of this topic, such as the mechanisms responsible for allocation tradeoffs that contribute to life-history trade-offs, and the endocrine regulation of life history specialization (see above references). Moreover, other important aspects of life history adaptation, such as the role of diurnal (daily-rhythmic) expression of life-history traits and the genes that contribute to them, remain virtually unstudied (Zera et al., 2017).

Wing polymorphism in insects has figured prominently in functional studies of life history adaptation. The polymorphism, which consists of a flight-capable and one or more flightless morphs that trade-off aspects of flight (production of wings, flight muscles, flight fuels; flight per se) for reproductive output, is a phylogenetically widespread adaptation of central importance in insects (Harrison, 1980; Hardie and Lees, 1985; Roff, 1986; Zera and Denno, 1997; Guerra, 2011; Zera and Harshman, 2001, 2009, 2011; Zera and Brisson, 2012). Extensive biochemical and physiological studies in Gryllus crickets have provided among the most detailed information on modifications of intermediary (e.g., lipid, amino-acid) metabolism and endocrine regulation that underlie life history specialization during adulthood (Table 1). However, endocrine and biochemical studies undertaken to date in Gryllus, while detailed, have primarily focused on one im-

portant hormone, juvenile hormone $(\mathrm{JH})$, and on a few pathways of 
Table 1. Morphological, physiological and life-history differences among the flight-capable [(LW(f)], the obligate flightless (SW) and the plastic-flightless [LW(h)] morphs of G. firmus during adulthood.

\begin{tabular}{|c|c|c|c|c|}
\hline \multirow[b]{2}{*}{ Trait } & \multicolumn{3}{|l|}{ Morph } & \multirow[b]{2}{*}{ References } \\
\hline & $\operatorname{LW}(f)$ & SW & $\operatorname{LW}(h)^{1}$ & \\
\hline Wings & Fully developed & Short & Fully developed & Zera et al., 1997 \\
\hline Flight muscles & $\begin{array}{l}\text { Fully developed; } \\
\text { functional }\end{array}$ & $\begin{array}{l}\text { Underdeveloped; } \\
\text { non-functional }\end{array}$ & $\begin{array}{l}\text { Histolyzed; } \\
\text { nonfunctional }\end{array}$ & $\begin{array}{l}\text { Zera and Denno, 1997; } \\
\text { Zera et al., } 1997\end{array}$ \\
\hline Capable of flight & Yes & No & No & Zera et al., 1997 \\
\hline Ovarian mass (day 5) & Small & $\begin{array}{l}\text { Large (ca. 3-4-fold } \\
\text { greater than LW (f)) }\end{array}$ & $\begin{array}{l}\text { Large - same } \\
\text { as SW }\end{array}$ & $\begin{array}{l}\text { Zera et al., 1997; } \\
\text { Zera and Larsen, 2001; } \\
\text { Zera, } 2005\end{array}$ \\
\hline Lipid levels & High & Low & Low & $\begin{array}{l}\text { Zera and Larsen, 2001; } \\
\text { Zera, } 2005\end{array}$ \\
\hline Lipid biosynthesis & High & Low & Low & $\begin{array}{l}\text { Zhao and Zera, 2002; } \\
\text { Zera, 2005; Zera and } \\
\text { Harshman, 2009, } 2011\end{array}$ \\
\hline Ovarian protein biosynthesis & Low & High & High & Zera and Zhao, 2006 \\
\hline Amplitude of JH titer cycle & Large & Small & Small & $\begin{array}{l}\text { Zhao and Zera, 2004; } \\
\text { Zera et al., 2007; Zera, } 2016\end{array}$ \\
\hline Blood ecdysteroid level & Low & High & $\begin{array}{l}\text { High } \\
\text { Zera et al., } 2007\end{array}$ & Zera and Bottsford, 2001; \\
\hline
\end{tabular}

1. The LW(h) morph is derived from the LW(f) morph by histolysis of flight muscles. Starting on day 3 of adulthood, an increasing frequency of LW(f) individuals are converted to the LW(h) morph as crickets age (Zera et al. 1997).

metabolism. Numerous other hormones, metabolic regulators, and enzymes of intermediary metabolism likely contribute significantly to life history adaptation, but have yet to be investigated in Gryllus.

The endocrine regulation of life history trait expression in adult Gryllus morphs has recently become an especially intriguing topic of investigation. Since the 196os, a widely held view has been that the insect hormone $\mathrm{JH}$ is a major regulator of morphological and life history differences between morphs of species exhibiting wing polymorphism, as well as other important polymorphisms/polyphenisms (Nijhout, 1994; Zera and Denno, 1997). However, recent detailed endocrine studies have called this hypothesis into question in Gryllus. The blood concentration of $\mathrm{JH}$ is now known to exhibit a dramatic circadian rhythm ( $>$ 10-fold change over several hours) in the dispersing morph of G. firmus, rising above and falling below the relatively constant titer in the flightless morph during the first week of 
adulthood (Zhao and Zera, 2004; Zera et al., 2007, 2017; Fig. 1). JH is now thought to play a more specialized role regulating traits involved in morph-dependent diurnal dispersal (exclusively at night; Zera et al., 2007, 2017; see Section 4). Other as yet unidentified hormones are expected to play a more important role than $\mathrm{JH}$ as regulators of traits that differ chronically (consistently over days without daily cycles) between the morphs, such as ovarian growth and lipid biosynthesis. The identity of the hormonal regulators of these "chronic" traits is now a central unresolved issue in life history endocrinology in Gryllus.

The documentation of the morph-specific JH titer circadian cycle in adult $G$. firmus has also made this species a useful empirical model to investigate diurnal/circadian aspects of life history adaptation. The majority of traits exhibit circadian rhythms or diurnal change (i.e., daily change which may be regulated by an endogenous circadian clock or exogenous environment variables) (Dunlap et al., 2004), and are thus expected to play an important role in life history adaptation (Zera et al., 2007, 2017). However, with some notable exceptions (Connor and Gracey, 2011; Beaver et al., 2002; Goodspeed et al., 2012; Hemond

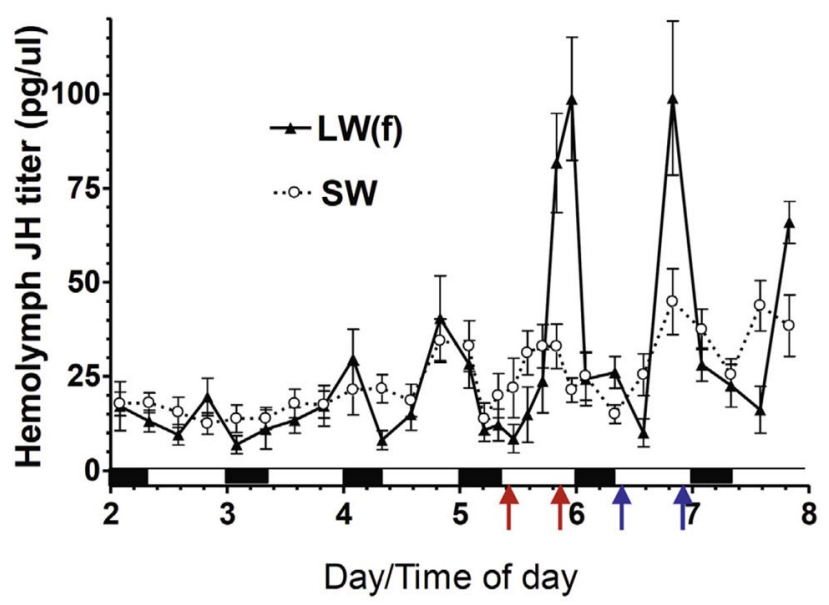

Fig. 1. Sampling schedule for RNA-seq and qRT-PCR experiments relative to the morph-specific JH titer circadian rhythm in flight-capable [LW(f)] and flightless (SW) morphs of G. firmus. Two arrows on day 5 (molt to adulthood= day o) indicate the time of day that fat bodies were taken from LW(f) and SW morphs for transcriptome profiling (RNA-Seq). Samples for qRT-PCR measurement of transcript abundance on day 5 (same time as samples taken for RNA-Seq) and day 6 were taken at the time-of-day denoted by the four red or blue arrows. In addition (not shown above), samples for qRT-PCR developmental profiles (see Fig. 5) were taken on day 1 of adulthood. Dark bar=scotophase (lights-off); white bar=photophase (lights on). $\mathrm{JH}$ titer data are from Zhao and Zera (2004). 
and Vollmer, 2015), the extent and significance of daily cycles of life history traits and their physiological underpinnings remain understudied. This is particularly the case for intraspecific variation in diel change, especially in a life history context, which has only been studied thus far with respect to the morph-dependent, genetically-based circadian rhythm for the hemolymph JH titer in G. firmus (Zera et al., 2007). Because JH, and hormones in general, regulate the expression of numerous genes in organisms (Goodman and Cousson, 2012; Jindra et al., 2013), morph-specific daily rhythms in the expression of functionally-important genes might be common in G. firmus.

Recent global studies of gene expression have provided an enormous amount of new information on the functional causes of life history adaptation that can be used for subsequent, more detailed hypothesis testing (St-Cyr et al., 2008; Wheat et al., 2011; Savolainen et al., 2013; Jones et al., 2015; Kvist et al., 2015). We recently used RNASeq to construct a de novo flight muscle and fat body transcriptome for G. firmus (Vellichirammal et al., 2014). We then used this transcriptome to identify genes differing in transcript abundance between these organs and between the morphs of this species. However, because of restricted sampling (one time point, one pair of dispersing and flightless stocks), only limited conclusions could be drawn regarding the generality of chronic morph differences in gene expression, and no information was available on diel change in gene expression in the study of Vellichirammal et al. (2014)

The present study had two main goals. The first was to document morph-specific developmental profiles for the expression of genes identified previously as potential contributors to chronic life history differences between morphs of G. firmus (Vellichirammal et al., 2014). We were particularly interested in identifying associations between morph-specific patterns of gene expression and ovarian growth, a key life history trait that, in turn, is correlated positively or negatively, with other important life history traits (e.g., accumulation of somatic triglyceride) (see Table 1). A diverse set of genes was studied, including those that encode hormones (e.g., insulin-like peptide), components of pathways of lipids metabolism not previously investigated (e.g., in glyceride biosynthesis), and proteins involved in other functions not previously studied in this dimorphism (e.g., regulators of glycolysis, clock function, and immunity). To further determine the functional bases of these associations, we also assessed the extent to which gene expression profiles changed in concert with the natural 
transformation of the dispersing morph into a flightless, high fecundity morph during adulthood by flight-muscle histolysis (see Section 2). The second main goal was to identify the extent to which morphs differ in diel change in gene expression and the extent to which these changes were correlated with the morph-specific JH titer circadian rhythm. Results of the present study provide new information regarding the differential expression of genes of potential functional importance with respect to life history specialization in morphs of G. firmus, especially with regard to endocrine regulation. In addition, the present study provides the first information on genetic polymorphism for diel change in gene expression, associated with genetic polymorphisms for a circadian rhythm in the hemolymph JH titer and life history traits.

\section{Materials and methods}

\subsection{Background on G. firmus morphs and artificially-selected populations}

Studies were conducted on the flight-capable and two flightless morphs of G. firmus, which are common in natural populations of this species. The flight-capable morph has fully-developed wings and large functional flight muscles [termed LW(f)] while the obligate flightless morph has short wings and underdeveloped, non-functional flight muscles (termed SW). In addition, like many other wing-polymorphic species (Zera and Denno, 1997; Zera et al., 1997), some LW(f) individuals spontaneously degenerate their flight muscles, but retain their wings during adulthood, producing a different flightless morph but with enhanced ovarian growth similar to the SW morph [termed LW (h)=long-winged, histolyzed flight muscle (Table 1)]. In addition to differences in wing length and flight muscle size and function, the flight-capable and flightless morphs differ in numerous physiological, biochemical, and endocrine traits related to dispersal and reproduction (Table 1). The flight-capable LW(f) morph flies exclusively during the night (Walker, 1986) and thus G. firmus exhibits morph-dependent diurnal dispersal by flight. The primary focus of the present study was comparisons between gene expression in LW(f) and SW females, with $\mathrm{LW}(\mathrm{h})$ examined to a lesser extent.

The G. firmus morphs used for this study were derived from two pairs (blocks, Bks) of large outbred laboratory populations that were 
founded by individuals collected in the field in the mid-1990s. These artificially-selected populations are part of a larger selection experiment on wing morph (Zera and Larsen, 2001; Zera, 2005; Zera and Harshman, 2009). Each block had been founded by taking a sample from a polymorphic base population; one portion of each sample was selectively bred for the LW(f) morph by breeding only LW(f) adults, while the other portion was selectively bred for the SW morph by breeding only SW adults. For many years, each LW(f) or SW population has consistently produced $>90 \%$ LW(f) or SW adult females, respectively. All lines have been maintained under a 16 light: 8 dark photoregime, at 26-28 ${ }^{\circ} \mathrm{C}$ and were fed a standard laboratory diet. These populations are the same as those investigated previously in numerous biochemical and physiological studies of morph adaptation (e.g., Zera and Larsen, 2001; Zhao and Zera, 2002; Zera and Zhao, 2003, 2006; reviewed in Zera and Harshman 2009, 2011; see Table 1). The RNA-Seq study was conducted on block-2 (Bk-2) LW(f) and SW populations, while the qRTPCR studies were conducted on Bk-2 and Bk-1 populations.

\subsection{Differential expression analysis}

\subsection{1. $R N A-S e q$}

We used RNA-Seq to quantify differences in global expression between morphs of $G$. firmus during two time points on day 5 of adulthood. This day was chosen for expression profiling since previous studies indicated large differences in ovarian growth and intermediary metabolism between the two morphs at this age (Zera, 2005; Zera and Harshman, 2009). Fat body samples from two time points, early (three to four hours after lights on, the 'AM' sample) and late in the photophase (within two hours prior to lights off, the 'PM' sample), were collected (see Fig. 1). These two time points were selected to test the hypothesis that gene expression profiles exhibited morphspecific diel patterns of variation that paralleled previously reported morph-specific circadian change in the hemolymph JH titer (Fig. 1), as opposed to exhibiting temporally-constant differences between the morphs. Three biological replicates per time point per morph were collected, with each replicate consisting of fat body dissected and flash frozen from a single female. cDNA libraries were constructed and sequenced on an Illumina Genome analyzer II flow cell, and the reads obtained were aligned to a de novo transcriptome (for detailed methods, see Vellichirammal et al., 2014). After alignment, read counts 
were exported to DESeq2 for differential expression analysis (Love et al., 2014). Only transcripts with an average read count greater than eight per sample across all samples were included in the analysis in order to focus on reasonably abundant transcripts. A transcript was considered differentially expressed if its false discovery rate (FDR) corrected $p$-value was $\leq 0.05$ using the Benjamini-Hochberg procedure (Benjamini and Hochberg, 1995). A preliminary analysis of morph differences in gene expression, not separated into AM and PM samples, was reported in Vellichirammal et al., 2014.

\subsection{2. $q R T-P C R$}

Nine genes were selected to more intensively investigate patterns of chronic (i.e. temporally-invariant) and diel gene expression differences between morphs. Fat bodies of each morph from Bk-2 populations (the same populations used in the RNA-Seq analysis, but different fat body samples) and Bk-1 populations (not previously studied) were collected on the first day of adulthood (day 1, day of molt=day $\mathrm{o}$; AM sample only) and during the AM and PM of each of two days (5 and 6) of adulthood (Fig. 1). We chose genes that exhibited strong differences in expression between the morphs independent of time of day in the preliminary RNA-Seq study. These included an endocrine regulator (ILP, insulin-like peptide), genes involved in lipid metabolism (GPAT, glycerophosphate acyltransferase; GPDH glycerophosphate dehydrogenase), and a gene involved in immunity (LEC, lectin-related protein). These genes were chosen to characterize morph differences in gene expression that potentially contributed to chronic morph adaptation (e.g., non-cycle morph differences in ovarian growth, lipid biosynthesis, etc.). Second, we chose genes that exhibited large diel (daily) change in expression on the one day of adulthood studied in the pilot RNA-Seq study (4-9 fold change between AM and PM samples: MAPK, Mitogen activated protein kinase; ACE, angiotensinogen converting enzyme; TIM, timeless; GLUC, glucose dehydrogenase; and PFK-2/FBP- 2; phosphofructokinase-2/fructose bisphosphatase-2). This was done to identify (1) morph-specific diel cycles in expression over several days of adulthood, (2) the consistency of gene-expression cycling profiles across multiple artificially-selected populations, and (3) the extent to which morph-specific diel cycles in gene expression paralleled morph-specific cycles of hemolymph JH titer.

Fig. 1 illustrates the sampling schedule for the qRT-PCR study (days 1,5 and 6 ) relative to the RNA-Seq study (day 5 only) and to the 
JH titer changes. Four biological replicates were collected per time point, with each replicate consisting of fat body from a single female. RNA was isolated from fat body using the RNeasy Mini kit (Qiagen). Extracted RNA was then DNase (Ambion) treated and converted to cDNA using random hexamer primers (Invitrogen) and Superscript II reverse transcriptase (Life Technologies, Inc.). Primers were designed using Primer3Plus (Untergasser et al., 2007) (Supplementary Table S1). qRT-PCR reactions were performed on a Real-Time PCR system 7500 (Applied Biosystems) using SYBR green PCR master mix (Applied Biosystems). Actin was selected as the reference gene based on our previous use of this gene and its stability across experiments (Vellichirammal et al., 2014). Each biological replicate was measured with two technical replicates and fold change was calculated using the $2^{-}$ $\Delta \Delta C \mathrm{C}$ method (Livak and Schmittgen, 2001).

\subsection{Characterizing gene expression cycling}

Expression of a gene was considered to exhibit a daily cycle if it met two criteria: (1) mean expression reversed direction during each consecutive sampling period (e.g., an increase from day 5 AM to day 5 PM, followed by a decrease to day 6AM and an increase to day 6PM; or the opposite pattern on each day), and (2) at least a 1.3-fold change in expression from AM to PM samples on each of days 5 and 6 . The latter requirement was used to eliminate genes that exhibited very weak cycles. Subsequent $\mathrm{X}^{2}$ tests were used to determine whether or not morphs differed in the proportion of cycling genes. To insure that the difference between morphs with regard to the proportion of cycling genes was not a spurious consequence of the specific fold-change in expression used to define a cycling gene, additional tests were conducted using more or less stringent criteria to define cyclicity. The more stringent definition required the same pattern of change described above plus a greater fold change in expression (1.5 fold) during each of days five and six. The less stringent definition only required that expression changed by the patterns described above, without any requirement of a minimum fold-change in expression. Results of statistical analyses were very similar using any of the three definitions of cyclicity (see Section 3 ). A one-tailed $\mathrm{X}^{2}$ test was used to determine whether the number of cycling genes differed between the morphs. This test was one-tailed based on the a priori expectation that the number of cycling genes would be greater in the LW(f) compared 
with the SW morph. Justification for this expectation was the prior observation that a significantly greater number of genes of the LW(f) morph compared to the SW morph exhibited diel change on one day of adulthood measured in the RNA-Seq experiment, undertaken prior to the qRT-PCR study (see Section 3).

\section{Results}

\subsection{Morph and time-of-day differences in gene expression de- termined by RNA-Seq on different times of one day (day-5) of adulthood}

We identified 10,777 genes, each of which was expressed in fat body from both LW(f) and SW morphs in both AM and PM time points of day 5 of adulthood. When these 10,777 genes were subjected to differential expression analysis, 3.0\% $(n=325$; AM sample $)$ and 4.9\% ( $n=531$; PM sample) differed in expression between the LW(f) and SW morphs at the same time of day (Supplementary Tables S2 and S3). A much greater number of genes (20.1\%; $n=2166$ transcripts) differed significantly in abundance between the two time points in either or both morphs (Fig. 2; Supplementary Tables S4 and S5). Of these, some transcripts exhibited significant daily change from AM to PM in both LW(f) and SW morphs (n=416, 3.9\%; Fig. 2; Supplementary Tables S6 and S7). More importantly, other transcripts changed significantly during the day in a morph-specific manner: A substantially greater percentage of genes exhibited diel change in expression in the LW(f) morph (14.2\%; $\mathrm{n}=1535)$ compared with the SW morph $(2 \%, \mathrm{n}=215)$ (Results of $\mathrm{X}^{2}$ test: $\mathrm{P}<0.0005$; Fig. 2; Supplementary Tables $\mathrm{S} 4$ and S5). This was also the case when the analysis was restricted to genes exhibiting larger-fold changes in gene expression: greater than 2.5 fold change in expression ( $\mathrm{LW}(\mathrm{f}), \mathrm{n}=500$; SW, $\mathrm{n}=206 ; P<0.0001$ ), or greater than 4 -fold change ( $L W(f), n=143$, SW, n=12; $P<0.0001$ ).

Not only was diel change in gene expression much greater for the LW(f) morph compared with the SW morph, the number of genes whose transcript abundance differed temporally in the LW(f) morph was significantly greater than the number of genes whose transcript abundance differed between the LW(f) and SW morphs at the same time of day. This was the case whether comparisons were made between LW(f)-AM versus LW(f)-PM samples (1951 genes exhibiting diel 

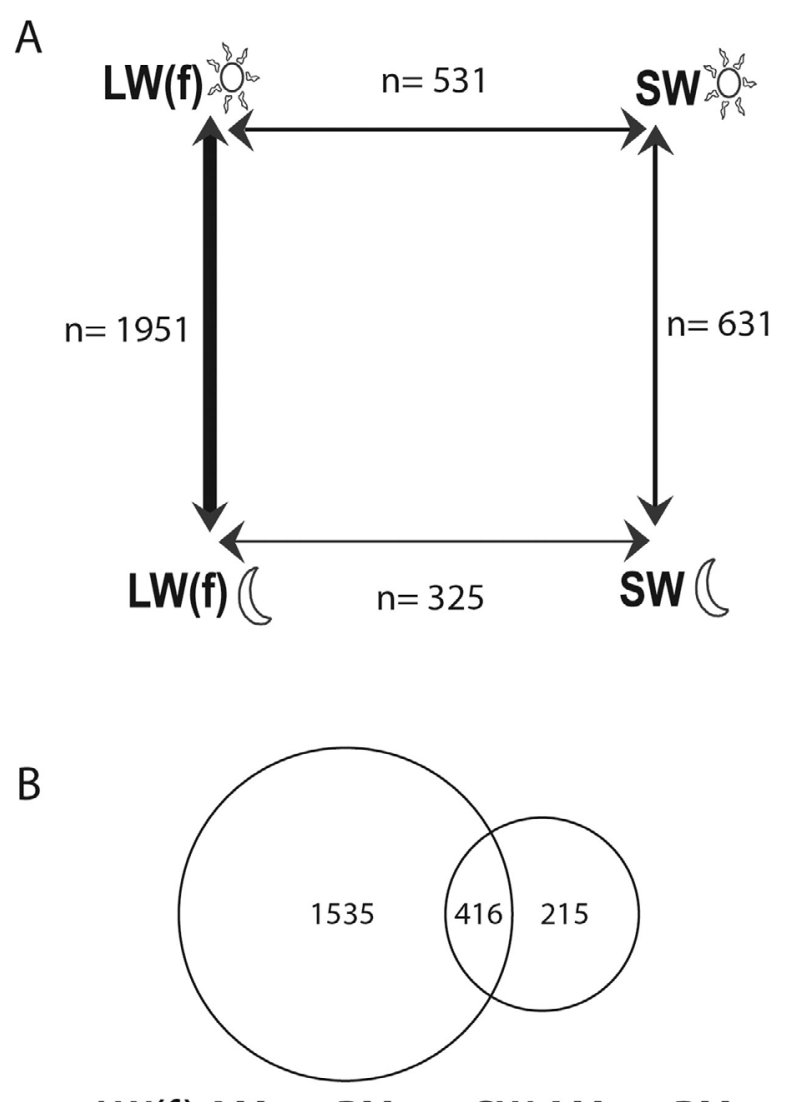

LW(f) AM vs. PM SW AM vs. PM

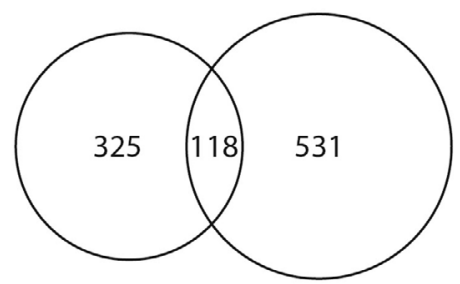

\section{AM LW(f) vs. SW PM LW(f) vs. SW}

Fig. 2. Panel A. Number of transcripts whose expression differed between LW(f) and SW female morphs at the same time of day compared with the number differing between the same female morph (LW(f) or SW) at different times of the same day. The sun symbol denotes the "AM sample" taken within $2 \mathrm{~h}$ after lights on, while the moon symbol indicates the "PM sample" taken within $2 \mathrm{~h}$ before lights off. Expression of the same 10,777 genes were measured in each morph and time point on day 5 of adulthood. Thickness of lines denote the relative number of gene expression differences which were much greater between the same morph at different times of day (especially the LW(f) morph) compared with different morphs at the same time of day. Panel B. Top: Overlap in gene expression differences between the same morph at different times of day. Bottom: Overlap in gene expression differences between different morphs at the same time of day. Numbers indicate genes with differential expression. See Section 3 for statistical analyses of these data. 
change) and LW (f) versus SW transcripts measured early in the photophase (AM samples: 325 genes differing between morphs; Results of $\mathrm{X}^{2}$ test: $\left.P<0.0001\right)$ or late in the photophase (PM samples: 531 gene differences; Results of $\mathrm{X}^{2}$ test: $P<0.0001$ ) (Fig. 2; Supplementary Tables S2-S5). Although of lesser magnitude than for the LW(f) morph, the number of genes whose transcript abundance changed during the day in the SW morph ( $n=531$; Fig. 2$)$ was also significantly greater than the number of genes that differed between LW(f) and SW morphs at the same time of day (Results of $\mathrm{X}^{2}$ test: $P<$ o.0001, AM sample; $P$ $<0.003$ PM sample). In other words, daily (diel) variation in gene expression within a morph was significantly greater than variation in expression between morphs at a particular time of day.

\subsection{Morph-specific differences in daily cycles of gene expression over a two-day period measured by qRT-PCR}

The diurnal change in gene expression within a morph between two time points on one day (day-5) of adulthood, measured by RNA-Seq, while consistent with a daily cycle in expression, could also result from a non-cyclic temporal change, such as a continuous increase or decrease in expression over several days. To more accurately determine the extent to which gene expression exhibits daily cycles, temporal patterns of gene expression for a diverse set of nine genes were quantified in more detail by qRT-PCR on an independent set of fat body samples measured at two time points per day (early and late in the photophase), in each of two days (days 5 and 6), in LW(f) and SW populations of two blocks (Bk-1 and Bk-2, see Section 2 and Table 2 ). As noted above, five genes were examined because of their previously observed diel variation (Fig. 3) and four genes because of their morph differences (Fig. 4).

A significantly greater number of genes exhibited a daily cycle in gene expression during days 5 and 6 of adulthood in the LW(f) morph (11 of 18; 9 genes scored in each of 2 blocks for each morph), compared with the SW morph (4 of 18; Table 2; Figs. 3-4; $\mathrm{X}^{2}$ test: $P=0.009$, one-tailed test). Similar results were observed when the less stringent criteria [LW(f): 13 of 18 genes cycling, SW: 6 of 18 genes cycling; $\mathrm{X}^{2}$ test: $\left.P<0.01\right]$, or more stringent criteria were used [LW(f): 8 of 18 cycling genes, SW: 2 of 18 cycling genes; $\mathrm{X}^{2}$ test: $P<0.015$; Table S8] to characterize cyclicity (see Section 2). For several genes (TIM, PFK-2/ FBP-2, and ILP), parallel cycles were observed in both LW(f) 

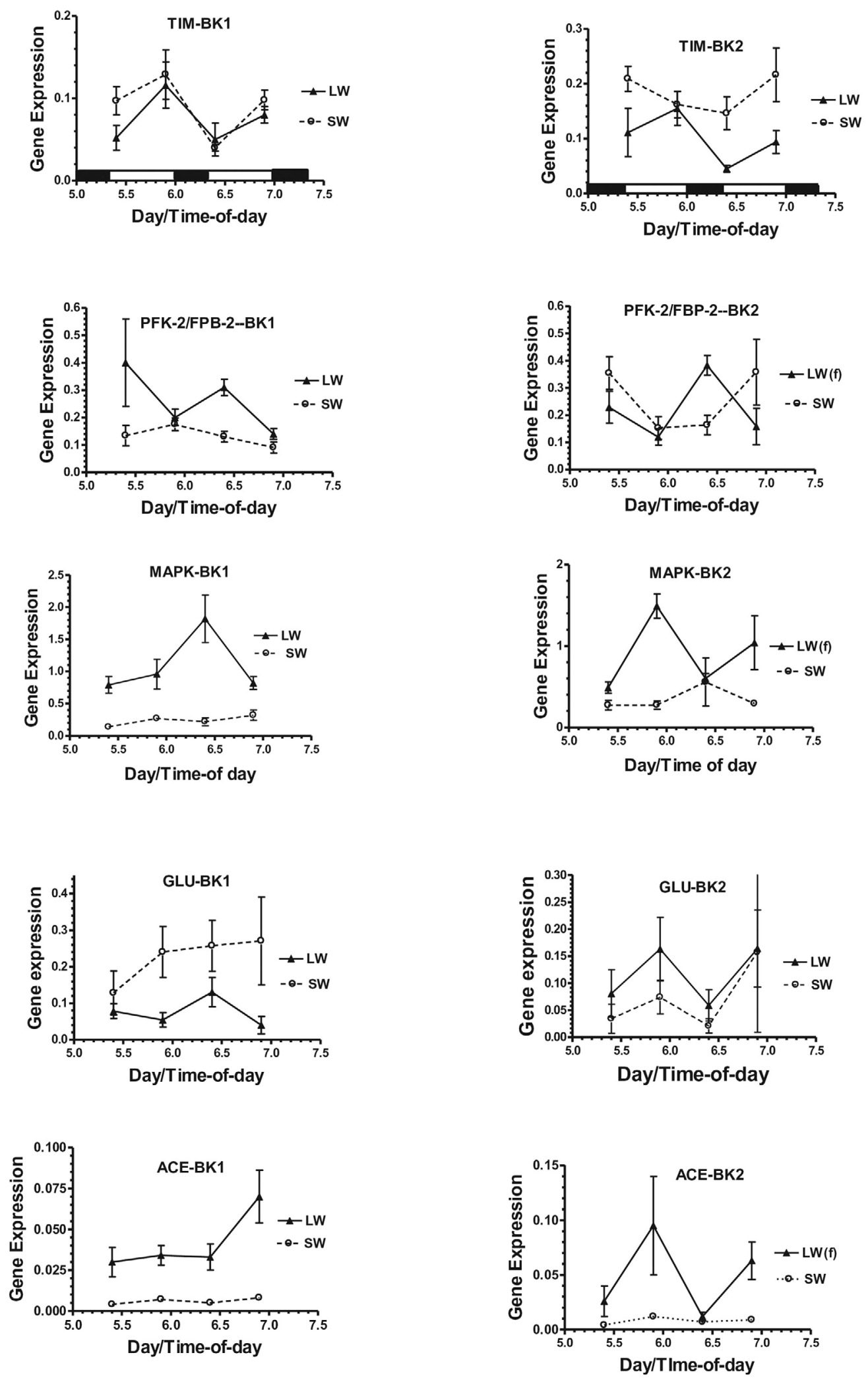
the exception of MAPK (but which did show significant diel change in Bk-2 LW(f) individuals). By contrast, nearly all of the genes that exhibited $<2$-fold diel change in gene expression in the RNA-Seq study did not exhibit cycling in gene expression over days 5 and 6 in any selected population when measured by qRT-PCR (Table 2). The difference in the proportion of genes that exhibited a daily cycle in expression for these two classes was statistically significant $\left(\mathrm{X}^{2}\right.$-test, $P$ $<$ o.o3; see legend of Table 2).

\subsection{Chronic (temporally-constant) differences in gene expression among flight-capable and flightless morphs of G. firmus mea- sured by $q R T-P C R$}

To investigate potentially chronic differences between the morphs throughout adulthood, gene expression data were pooled for the AM and PM time points across the two blocks for each morph for days 5 and 6 of adulthood; gene expression on day 1 was also included in the analysis (Fig. 5). Expression data for GLUC (full name for each gene studied is given in the footnote of Table 2) were not pooled across blocks because rank-order profiles for the morphs were in the opposite direction in the two blocks (see Fig. 3). With the exception of TIM, expression was low and equivalent for both morphs at the beginning

Fig. 3. Expression profiles of genes in LW(f) and SW morphs of G. firmus during early and late portions of the photophase of days 5 and 6 of adulthood. Values on the $\mathrm{x}$-axis refers to time intervals of days 5 and 6 of adulthood, and the periods of time when lights were on (open rectangles) or off (closed rectangles). $5.0=$ midnight of day 5 , and 5.5=noon of day 5 , with corresponding values for day 6 . Lights were off from midnight to $8 \mathrm{am}$, and fat body for gene expression was removed $1-2 \mathrm{~h}$ after lights on and 1-2 $\mathrm{h}$ before lights off, the same times-of-day that JH titers were previously measured [see Fig. 1, Zhao and Zera (2004), and Zera and Zhao (2008)]. Although not shown for the other panels of Fig. 3 and panels of Fig. 4, lights-on and lights-off occurred at the same time of day as the top two panels of Fig. 3. Genes in this figure exhibited large ( $>2$ fold) change in diel (daily) expression on day 5 in Bk-2 LW (f) and SW populations in the prior RNA-seq study. Note the greater number of genes that exhibit daily cycles in expression (1) in LW (f) compared with SW populations and (2) compared to genes in Fig. 4 which exhibited small or no diel change in expression in the prior RNA-Seq study. See Table 3 and Section 3 for characterization of cyclicity of individual genes and statistical analyses. 

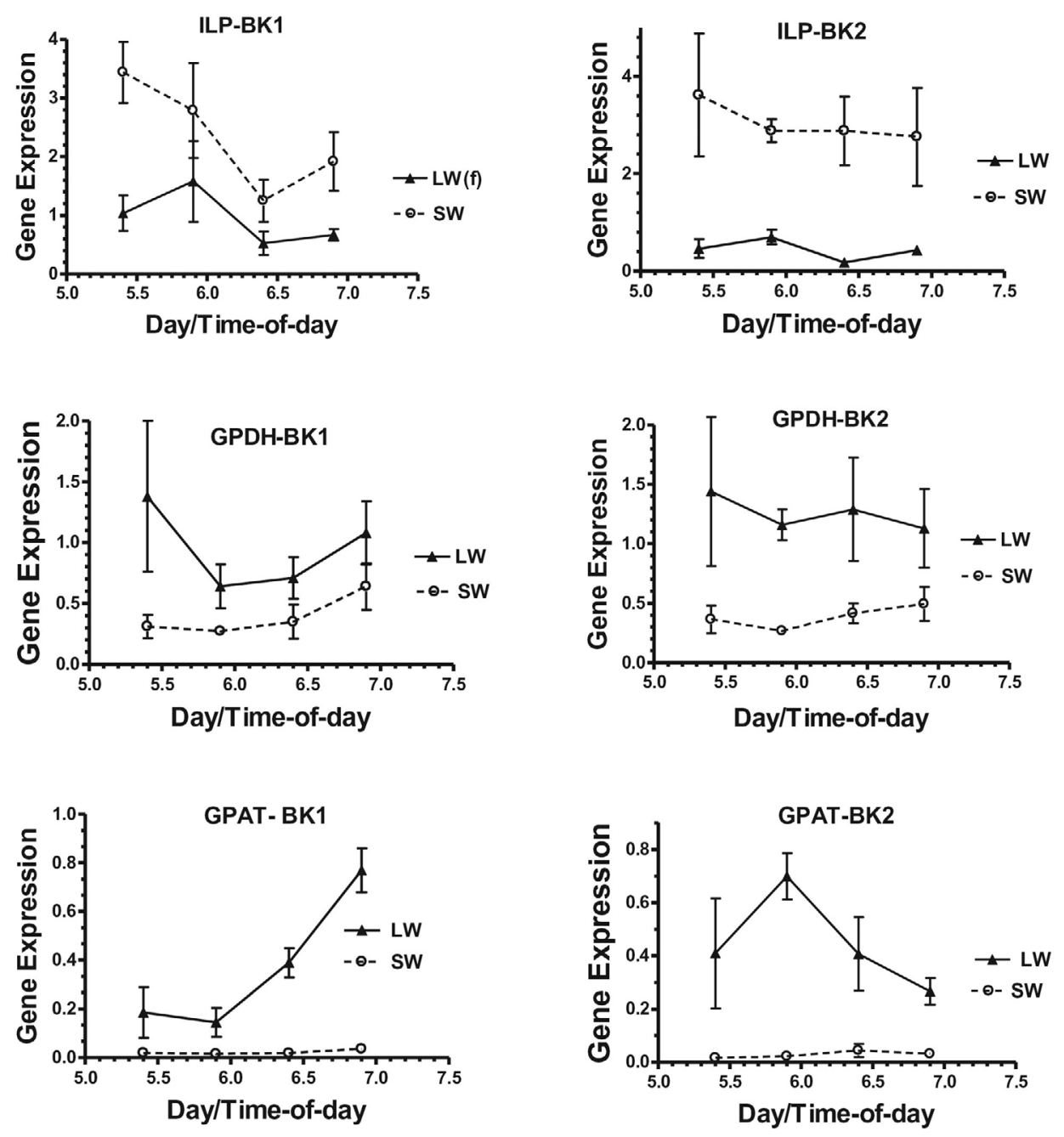

\section{LEC-BK1}
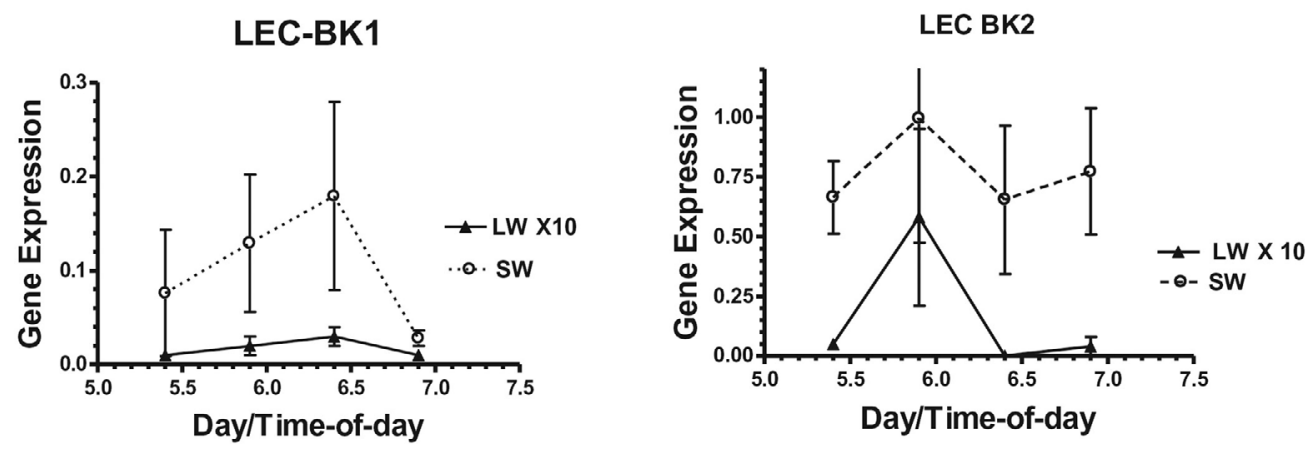

Fig. 4. Expression profiles of genes in LW(f) and SW morphs of G. firmus during early and late portions of the photophase of days 5 and 6 of adulthood. Genes in this figure exhibited small ( $<2$ fold) or no change in diel (daily) expression on day 5 in Bk-2 LW(f) and SW populations in the prior RNA-seq study. Note the smaller number of genes that exhibit daily cycles in expression compared to genes in Fig. 3 which exhibited larger ( $>2$ fold) diel change in expression in the prior RNA-Seq study. See Table 3 and Section 3 for characterization of cyclicity of individual genes and statistical analyses. 
(day 1) of adulthood (Fig. 5; $P>0.4$ for each gene except for TIM (P $<$ o.05)). Gene expression rose and diverged, often substantially, between the LW(f) and SW morphs on days 5 and 6 of adulthood (results of $t$-tests: $P<0.005$ for each gene except for PFK-2/FBP-2 $(P=0.242)$.

Morph-specific patterns of gene expression closely paralleled the morph-specific pattern of ovarian growth, a key life history trait that differs between the morphs. Ovarian mass was identical at the adult molt $(P>0.3, t$-test) and increased to a much greater degree in the

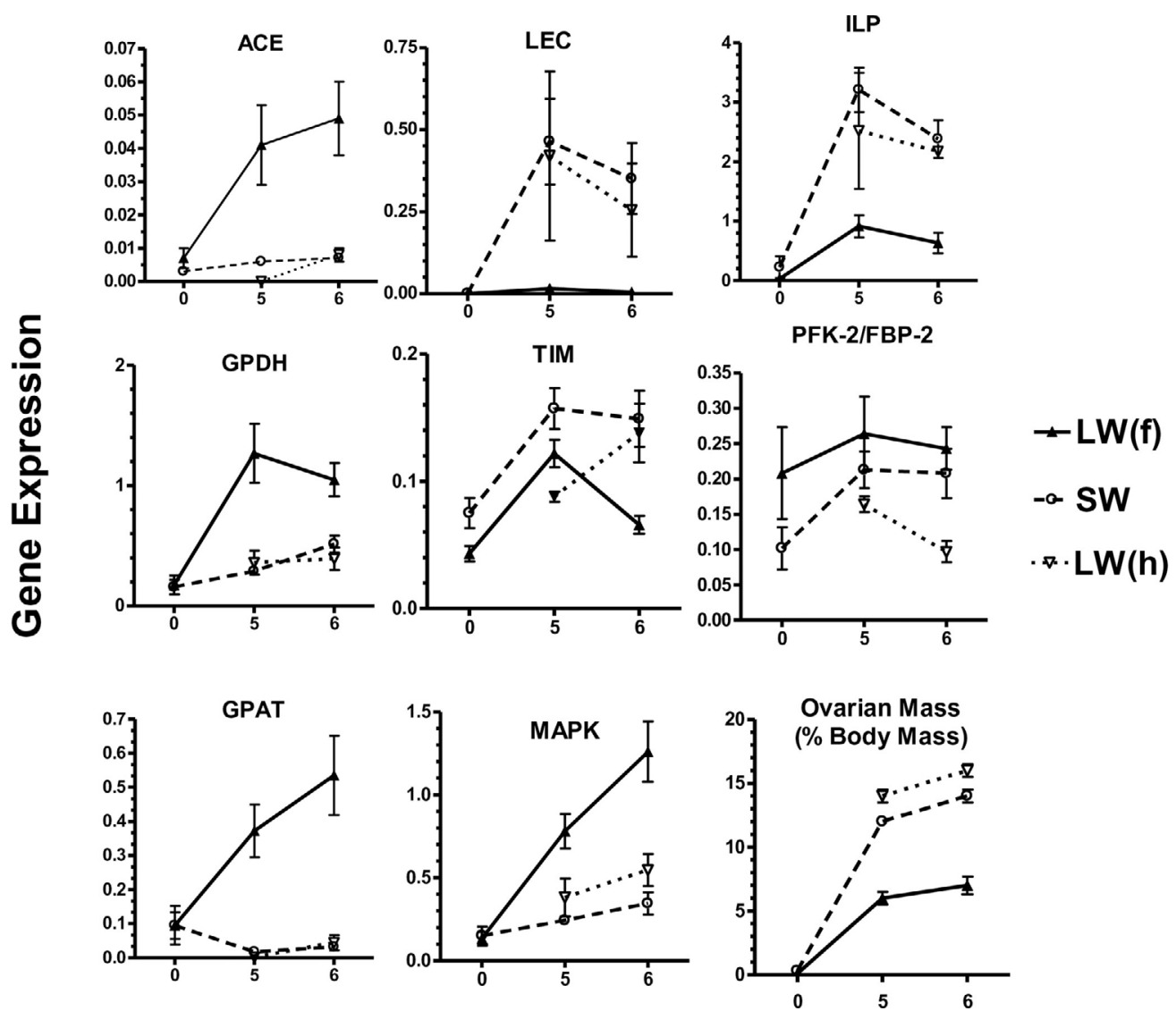

\section{Age of Adulthood (Days)}

Fig. 5. "Chronic" (consistent, independent of block and time-of-day) differences in gene expression and ovarian mass among the flight capable [LW(f)], obligate flightless [SW] and plastic flightless [LW(h)] morphs of Gryllus firmus during adulthood. The LW(h) morph is produced from the LW(f) morph, starting on day 3 of adulthood, and thus no data are available for the LW(h) morph on day 1. See Section 3 for statistical analyses. Values are means \pm SEM based on $45 \mathrm{LW}(\mathrm{f}), 47 \mathrm{SW}$ and 7 LW(h). See Table 1 for morph characteristics and Table 3 for full names of genes. To facilitate comparisons of "chronic" differences among morphs expression data was pooled across the two blocks times-of-day and blocks. Se Figs. 3 and 4 for expression data for individual blocks and times-of-day. 
flightless SW compared to the LW(f) morph $(P<0.005, t$-test $)$. In some cases, morph-specific gene expression positively co-varied with ovarian growth (e.g., ILP and ovarian growth were both substantially higher in SW compared with LW(f) females), while in other cases expression negatively co-varied with ovarian mass (e.g., GPDH and GPAT were higher and ovarian growth was lower in LW(f) compared with SW females (Fig. 5)).

Finally, the developmental profiles of gene expression of the "plastic" flightless morph [LW(h)], which is produced from the dispersing LW(f) morph during adulthood (see Section 2), closely paralleled the profiles of gene expression found in the other ("obligate") flightless SW morph. The only exceptions were TIM on day 5 and PFK-2/FBP-2 on day 6 (Fig. 5). In all cases, except for TIM $(P=.21)$, gene expression for the LW(h) morph differed significantly from the LW(f) morph $(P<$ 0.05 . $t$-tests $)$, and in all cases, except for MAPK $(\mathrm{P}=0.03)$, gene expression did not differ between the two flightless morphs $(P>0.4 ; \mathrm{P}=0.08$ for PFK-2/FBP-2). Thus, in nearly all cases, when the dispersing LW(f) morph was transformed into the flightless $\mathrm{LW}(\mathrm{h})$ morph during early adulthood, expression profiles of most genes also changed from the pattern seen in the LW(f) morph to that of the flightless SW morph.

For 6 of 8 genes, strong parallel gene expression differences between the LW(f) and SW lines were observed across the two blocks (MAPK, GPDH, GPAT, ILP, ACE, LEC; Figs. 3 and 4), which is consistent with these differences being genetic (i.e., indirect responses to direct selection on morph type). Gene expression profiles for GLU and PFK-2/FBP-2 differed from this general pattern. For GLU, as mentioned previously, developmental profiles differed between the morphs, but in opposite directions in the two blocks: expression was higher in the LW(f) than in the SW morph in block-1, but lower in block-2 (Fig. 3). For PFK-2/FBP- 2, consistent chronic gene expression differences between LW(f) and SW morphs were not observed between the blocks (Fig. 3).

\subsection{Gene expression correlations}

Correlations between transcript abundance for the nine genes and ovarian mass in the three morphs on days 5 and 6 of adulthood were estimated to ascertain the potential existence of functional relationships (Table 3). ILP exhibited the highest number of significant correlations (5), while GLUC-DH and PFK/FBP exhibited no significant 
Table 3. Correlations between transcript abundance of nine genes and ovarian weight in G. firmus.

\begin{tabular}{|c|c|c|c|c|c|c|c|c|c|}
\hline Gene & $\mathrm{ACE}$ & LEC & ILP & TIM & GPAT & GLUC & GPDH & MAPK & PFK-2/FBP-2 \\
\hline $\mathrm{ACE}$ & - & & & & & & & & \\
\hline LEC & -0.201 & - & & & & & & & \\
\hline ILP & -0.324 & 0.392 & - & & & & & & \\
\hline TIM & 0.016 & 0.493 & 0.472 & - & & & & & \\
\hline GPAT & 0.794 & -0.273 & -0.446 & -0.032 & - & & & & \\
\hline GLUC & -0.004 & -0.094 & 0.213 & 0.001 & -0.106 & - & & & \\
\hline GPDH & 0.416 & -0.292 & -0.373 & -0.009 & 0.639 & -0.030 & - & & \\
\hline MAPK & 0.376 & -0.297 & -0.398 & -0.323 & 0.413 & -0.154 & 0.329 & - & \\
\hline PFK-2/FBP-2 & -0.100 & 0.123 & 0.190 & 0.036 & -0.088 & 0.174 & 0.175 & 0.185 & \\
\hline OV-WT & -0.383 & 0.545 & 0.448 & 0.300 & -0.463 & 0.105 & -0.467 & -0.454 & 0.096 \\
\hline
\end{tabular}

Correlations were estimated on pooled data for LW(f), LW(h) and SW morphs from Bk-1 and Bk-2 on days 5 and 6 of adulthood. N=80; Bold values are significant ( $P<0.05, p$ values were corrected for experiment-wise error).

OV-WT=ovarian weight scaled to body weight. See Table 3 for full names of genes.

correlations. The following notable correlations were observed: Transcript abundance of GPAT and GPDH, two genes in the glyceride pathway, were positively correlated with each other and with ACE, a hormonal regulator. LEC was significantly positively correlated with the hormonal regulator, ILP, and the clock gene, TIM. Finally, the hormonal regulator ILP was positively correlated with TIM, negatively correlated with GPAT, and negatively correlated with MAPK. As is evident in Fig. 5, ovarian mass was positively correlated with the expression of LEC and ILP, and negatively correlated with ACE, GPAT, GPDH, and MAPK. The potential functional significance of these correlations is discussed below.

\section{Discussion}

\subsection{Chronic developmental differences in gene expression be- tween adult morphs}

Previous functional studies of morph differences in G. firmus related to aspects of dispersal, life-history, and development primarily focused on one aspect of intermediary metabolism, the fatty acid biosynthetic portion of lipid metabolism, and one hormone, JH (Table 1). In addition, these studies almost exclusively focused on morph-specific differences in protein function (e.g., enzyme activity) and aspects of systemic physiology (blood hormone levels, whole-organism lipid biosynthesis), with few molecular studies. The transcriptome study 
of Vellichirammal et al. (2014) and the present study provide a wealth of new information on a functionally diverse set of genes that differ chronically in expression between the morphs, and which potentially contributes to chronic life history differences between the morphs.

Adult developmental profiles of most of the nine genes examined in detail here strongly co-varied with morph-specific developmental profiles of ovarian growth (Fig. 5), consistent with these genes contributing to morph differences in ovarian growth or correlated life history traits (lipid or fatty acid biosynthesis; discussed in more detail below). Parallel, rank-order differences in chronic gene expression between LW(f) and SW lines of both blocks for six of nine genes (Figs. 3 and 4) are consistent with these morph differences in gene expression being genetic.

The importance of morph differences in chronic gene expression is strengthened by the results of the morph-transformation study (Fig. 5). As noted previously, the flightless LW(h) morph is generated from the LW(f) morph during adulthood by histolysis of the flight muscles. This "plastic flightless" LW(h) morph exhibits many traits that are much more similar to the "obligate flightless" (SW) morph, which never attains flight capability, than to the dispersing (LW(f)) morph from which the LW(f) morph is derived, most notably enhanced ovarian growth and reduced lipid production (Table 1). In the flightless LW(h) morph, adult patterns of ovarian growth and gene expression are both shifted from those seen in the dispersing LW(f) morph to those seen in the obligate flightless SW morph (Fig. 5).

These results on "chronic" (consistent over several days independent of time of day) morph differences in gene expression on days 5-6 of adulthood are especially important given the recent uncertainties regarding the endocrine regulation of "chronic" morph-specific traits on those days in G. firmus by JH (see Introduction and below). Of particular note was the chronically elevated expression of the ILP gene in the SW morph. Elevated ILP expression in the SW morph strongly parallels the substantially elevated ovarian growth and substantially reduced expression of GPDH and GAPT (involved in lipid biosynthesis, see below) in that morph (Fig. 5; Table 3). The homolog of the G. firmus ILP gene exhibits an analogous phase-specific pattern of expression in the locust $S$. gregaria: ILP expression is much higher in the gregarious phase, which exhibits enhanced ovarian growth, relative to the solitary phase (Badisco et al., 2008). RNAi knockdown of this gene in the gregarious phase of $S$. gregaria substantially reduces 
ovarian growth, suggesting that modulation of expression of ILP is involved in regulation of phase-dependent ovarian growth in this species (Badisco et al., 2011). Furthermore, in other insect species, reduced ILP is associated with increased accumulation of triglyceride (Tatar et al., 2001; Broughton et al., 2005; Sim and Denlinger, 2013). In G. firmus, ILP expression was also strongly correlated with expression of MAPK (Table 3), a key growth-regulating pathway that interacts with the insulin signaling pathway (Nijhout and Callier, 2013; Badisco et al., 2013), and MAPK expression also differed substantially between the morphs (Figs. 3 and 5). These data collectively suggest that ILP, possibly acting through MAPK, may play an important role regulating the trade-off (i.e., the negative association) between ovarian growth and triglyceride production in flight-capable [LW(f)] and flightless morphs [SW and LW(h)], by simultaneously enhancing ovarian growth and down-regulating genes involved in lipid biosynthesis such as GPAT and GPDH. Interestingly, modulation of the expression of ILP receptors has been reported to underlie morph induction in a planthopper (Xue et al., 2015), suggesting that ILP might regulate many aspects of wing polymorphism in various insect groups. Although the morph-gene expression associations in G. firmus presented here are purely statistical, they are important in that they set the stage for detailed functional studies to investigate the endocrine and biochemical aspects of this key trade off in G. firmus.

The substantially higher expression of two genes involved in glyceride biosynthesis (GPDH and GPAT; Fig. 5) in LW(f) compared with SW or LW(h) is also noteworthy. This finding is consistent with the greater rate of triglyceride biosynthesis measured previously in the LW (f) morph (Zhao and Zera, 2002; Zera, 2005; Zera et al., 2017). More importantly, these results suggest that a different portion of the lipid biosynthetic pathway may be a more important contributor to morph differences in triglyceride production than previously suspected. Specifically, two portions of the lipogenic pathway are involved in triglyceride production: The first (de novo fatty acid biosynthesis) produces fatty acid, while the second (glyceride pathway) links three fatty acids to a glycerol-phosphate molecule. Previous biochemical studies of morph-specific lipid biosynthesis focused exclusively on enzymes of the fatty acid biosynthetic pathway (Zera and Zhao, 2003; Zera, 2005). The present study identified much larger (typically $>4-10-$ fold) morph differences in expression of two genes involved in glyceride biosynthesis (Figs. 4 and 5) compared to activities of enzymes 
of fatty acid biosynthesis ( $<2$ fold difference between morphs (Zera and Zhao, 2003; Vellichirammal et al., 2014)). This suggests that evolutionary down-regulation of the glyceride biosynthetic portion of the lipogenic pathway may have been especially important in the evolution of reduced biosynthesis of triglyceride flight fuel in the SW morph, which allowed increased diversion of nutrients to egg production. In addition, expression of the neurohormone gene, ACE (angiotensinogen-converting enzyme) was much higher in the LW(f) morph (Figs. 3 and 5), in addition to being highly correlated with GPAT and GPDH expression. This suggests that ACE may also be involved in morphspecific regulation of lipid biosynthesis (see below for additional discussion of the function of this gene). These results provide the basis for future studies of the biochemical basis of morph- adaptation involving genes/enzymes of the glyceride pathway.

Several other transcriptomic comparisons of flight-capable and flightless morphs of wing polymorphic insects (Brisson et al., 2007; Yang et al., 2014; Shang et al., 2016) have also identified differential expression of genes involved in lipid metabolism and transport. Thus, modification of lipid metabolism appears to be an important general aspect of morph specialization for wing polymorphic species from diverse taxa. A novel aspect of the present study is that differences in lipid metabolism can be attributed to a specific organ, fat body, while the aphid studies were all conducted RNA extracts of whole bodies or body parts (e.g. thorax). A very different set of genes differs in expression between functional and non-functional flight muscles than fat body of the LW(f) and LW(h) morphs of G. firmus (Vellichirammal et al., 2014).

Finally, LEC, a gene implicated in immunity (Wilson et al., 1999) exhibited the highest magnitude difference in expression of the nine genes studied (Vellichirammal et al., 2014), typically with>15-50 fold higher expression in the flightless SW morph; Fig. 4). This suggests that morph-specific differences in immunity, a previously unstudied aspect of wing polymorphism in Gryllus may be a particularly important aspect of morph adaptation. If so, this would be similar to the proposed role of this gene in enhanced immunity in the gregarious phase of the desert locust (Badisco et al., 2008), a phenotype similar in many aspects to the flightless morph of wing-polymorphic species such as Gryllus (Vellichirammal et al., 2014). 


\subsection{Morph differences in daily rhythms of gene expression}

The high-amplitude, morph-specific circadian rhythm for the important insect hormone, $\mathrm{JH}$, in the wing-polymorphic cricket G. firmus (Zhao and Zera, 2004; Zera et al., 2017; Fig. 1) raised the possibility that daily rhythms in expression of a variety of genes might exist in G. firmus. In this and other Gryllus species, flight occurs in a morph-specific circadian manner, only in the LW(f) morph, and only at night (Walker, 1986). JH co-ordinates many behavioral, neural, and metabolic traits, that are related to flight (flight muscle characteristics, flight propensity and duration, flight energetics and metabolic preparation for flight) (Rankin, 1978; Pener, 1985; Rankin and Burchsted, 1992). Thus, we hypothesized that the JH titer cycle in the LW(f) morph of G. firmus potentially co-ordinates the expression of various components of cyclic daily flight in that morph, by directly or indirectly influencing gene expression. A first step in testing this hypothesis involved measuring the extent to which morph-specific cycles of gene expression correlate with the morph-specific JH titer cycle, an important focus of the present study.

A major finding of the present study was the greater number of genes exhibiting either diel (daily) change in expression on one day (day-5; Fig. 2, Section 3), or daily cyclic gene expression on multiple days in the LW(f) morph compared to the SW morph of G. firmus (Figs. 3 and 4; Table 2) which paralleled the morph-specific JH titer circadian rhythm (Fig. 1). Of particular note were the genes PFK-2/ FBP-2, a key regulator of the relative flux through glycolysis vs. gluconeogenesis (Pilkis et al., 1995), and ILP. Expression of both of these genes cycled in both LW(f) and in neither (SW) artificially-selected lines of G. firmus (Figs. 3-4). Thus genetic stocks of G. firmus exhibit co-varying genetic polymorphisms for (1) expression of two cycling genes, (2) the JH titer circadian rhythm, and (3) morph expression (Section 3 and Zera and Zhao, 2009). We know of no other example of polymorphic daily rhythms for gene expression within a species, let alone daily-rhythmic expression polymorphisms that are associated with an ecologically important life history polymorphism. In other cases, cyclic versus noncyclic patterns of gene expression were observed in LW(f) vs. SW lines of one block but not the other (e.g., $\mathrm{MAPK})$; in one case anti-parallel cycles were observed in the same morph in different blocks (e.g., GLU). 
The morph-specific patterns of gene expression could be due to any number of non-mutually exclusive causes, the most likely of which are the direct effect of $\mathrm{JH}$ cycling on gene expression, or the action of regulators that co-ordinately regulate cycles of $\mathrm{JH}$ and expression of other genes. A number of studies have reported functional interactions between the JH and ILP (Tatar et al., 2001; Flatt et al., 2005; Tu et al., 2005; Wu and Brown, 2006). Thus, the cycling of ILP gene expression in the LW(f) but not the SW morph (Fig. 3) could be caused by morph-specific cycling of the JH titer. Alternatively, the arrow of causality could be reversed, with morph-specific cycling of ILP regulating morph-specific cycling of JH. In addition, as mentioned above, MAPK is a key downstream component of the insulin signaling pathway (de Paula et al., 2008; Taniguchi et al., 2006), thus providing a functional explanation for the cycling of MAPK in LW(f) but not SW morphs of Bk-2 lines.

A number of other genes that exhibit morph-specific cycles also have regulatory functions (e.g., ACE and TIM), and may function together with $\mathrm{JH}$ as regulators of morph-specific circadian traits in $G$. firmus. ACE is a phylogenetically-widespread peptidase that regulates neurohormones involved in reproduction and possibly other physiological processes (Issac et al., 1999, 2007). ACE is more highly expressed in newly founded vs. longer-established populations of the Glanville fritillary butterfly, and may regulate differences in the timing of egg maturation observed between these two population types (Wheat et al., 2011).

While we have clearly identified a set of functionally-important genes that exhibit morph-specific patterns of daily cycling, the extent to which this set of genes is representative of the transcriptome as a whole is unknown at present. The positive association between moderate-high fold change in gene expression measured in the RNA-Seq study and the existence of a daily cycle in gene expression measured by qRT-PCR (Section 3 and legend of Fig. 3), suggests that a significant proportion of the transcriptome may cycle in a morph-specific manner. On the other hand, the number of genes sampled was too small to definitively extrapolate to the transcriptome as a whole. Future, more detailed studies of gene expression in morphs of G. firmus will be required to settle this issue. 
4.3. Importance of investigating daily cycles of gene expression in ecological-genomic studies

The greater number of genes exhibiting daily change in expression within a particular morph compared to the number whose expression differed between the LW(f) and SW morphs at the same time of day (Fig. 2; Section 3) has important implications for current studies of molecular adaptation. This suggests that, in G. firmus, diel change in gene expression within a single phenotype, the LW(f) or SW morph, may be as, or more, prominent a feature of adaptive gene expression as differences in gene expression between LW(f) and SW morphs measured at the same time of day. Phenotypic differences measured at one time point have been virtually the entire focus of previous functional studies of wing polymorphism in Gryllus (Table 1). Daily change in gene expression should be an important general aspect of functionalgenomic studies in natural populations. Although an increasing number of studies investigate the molecular adaptation in natural populations (e.g., St-Cyr et al., 2008; Wheat et al., 2011; Savolainen et al., 2013; Jones et al., 2015; Kvist et al., 2015), the vast majority of these studies have not investigated the possible existence of daily rhythms in gene expression (for notable recent exceptions see: Connor and Gracey, 2011; Goodspeed et al., 2012; Hemond and Vollmer, 2015).

In conclusion, the present study provides new information on various molecular aspects of morph adaptation for dispersal (e.g., glyceride biosynthesis) versus reproduction (ILP regulation of ovarian growth) in G. firmus. In addition, this study provides some of the first information on genetically variable daily rhythms in gene expression, and their potential role in life history and endocrine adaptation. These data are not only important for the field of life history evolution where circadian adaptation has largely been ignored, but also for the field of chronobiology where adaptive daily rhythms in gene expression and endocrine regulation, especially intraspecific variation in a life-history context, remain understudied.

\section{Data accessibility}

The raw sequence reads in this study are deposited in NCBI's Short Read Archive (SRA) under BioProject id PRJNA198853, with sample identifiers SAMNo2058407 to SAMNo2058428. 
Acknowledgements - Research was supported by NSF grant IOS-1122075 and funds from the School of Biological Sciences, University of Nebraska-Lincoln to AJZ, and startup funds from the Department of Biology, University of Rochester to JAB. We thank K. Williams for excellent technical assistance.

Appendix A. Supplementary data - Nine files of supplementary data are attached to the archive main page for this article, as follows:

Supplementary data 1. List of primers designed for qRT-PCR. Word document (12KB)

Supplementary data 2. Comparison of gene expression differences between the LW(f) and SW morphs of G. firmus measured early in the photophase (AM) of day 5 of adulthood.

Spreadsheet (41KB)

Supplementary data 3. Comparison of gene expression differences between LW(f) and SW morphs measured late in the photophase (PM) of day 5 of adulthood.

Spreadsheet (43KB)

Supplementary data 4. Comparison of gene expression differences in the LW(f) morph of G. firmus between early (AM) and late (PM) in the photophase of day 5 of adulthood.

Spreadsheet (136KB)

Supplementary data 5. Comparison of gene expression differences in the SW morph of G. firmus between early (AM) and late (PM) in the photophase of day 5 of adulthood.

Spreadsheet (48KB)

Supplementary data 6. Genes that were commonly upregulated in the late photophase (PM) of the 5th day of adulthood in SW nd LW(f) morphs.

Spreadsheet (19KB)

Supplementary data 7. Genes that were commonly upregulated in the early photophase (AM) of the 5th day of adulthood in SW and LW(f) morphs.

Spreadsheet (16KB)

Supplementary data 8. Characterization of gene expression in LW(f) and SW lines of G. firmus as being cyclic or non-cyclic using the "more stringent" or "less stringent" criteria than those used in the "standard" method.

Word document (15KB)

Supplementary data 9. Mean expression $( \pm$ SEM) of nine genes in two pairs of LW(f) and SW selected lines that were used to construct Figs. 3-5.

Word document (17KB) 


\section{References}

Beaver, L.M., Gvakharia, B.O., Vollintine, T.S., Hege, D.M., Stanewsky, R., Giebultowicz, J.M., 2002. Loss of circadian clock function decreases reproductive fitness in males of Drosophila melanogaster. Proc. Natl. Acad. Sci. U.S.A. 99, 2134-2139.

Badisco, L., Claeys, I., Van Hiel, M., Clynen, E., Huybrechts, J., et al., 2008. Purification and characterization of an insulin-related peptide in the desert locust, Schistocerca gregaria: immunolocalization, cDNA cloning, transcript profiling and interaction with neuroparsin. J. Molec. Endocrinol. 40, 137-150.

Badisco, L., Marchal, E., Van Wielendaele, P., Verlinden, H., Viegels, R., Vanden Broeck, J., 2011. RNA interference of insulin-related peptide and neuroparsins affects vitellogenesis in the desert locus Schistocerca gregaria. Peptides 32, 573-580.

Badisco, L., Van Wielendaele, P., Vanden Broeck, J., 2013. Eat to reproduce: a key role for the insulin signaling pathway in adult insects. Front. Physiol. 4, 1-16.

Benjamini, Y., Hochberg, Y., 1995. Controlling the false discovery rate: a practical and powerful approach to multiple testing. J. R. Stat. Soc. Series B-Methol. 57, 289-300.

Brisson, J.A., Davis, G.K., Stern, D.L., 2007. Common genome-wide transcription patterns underlying the wing polyphenism and polymorphism in the pea aphid (Acyrthosiphon pisum). Evol. Dev. 9, 338-346.

Broughton, S., Piper, M., Ikeya, T., Bass, T.M., Jacobson, J., et al., 2005. Longer lifespan, altered metabolism, and stress resistance in Drosophila from ablation of cells making insulin-like ligands. Proc. Natl. Acad. Sci. U.S.A. 102, 3105-3110.

Connor, K.M., Gracey, A.Y., 2011. Circadian cycles are the dominant transcriptional rhythm in the intertidal mussel Mytilus californianus. Proc. Natl. Acad. Sci. U.S.A. 108, 16110-16115.

de Paula, R., Lamb, T.M., Bennett, L., Bell-Pedersen, D., 2008. A connection between MAPK pathways and circadian clocks. Cell Cycle 7, 2630-2634.

Dunlap, J.C., Loros, J.J., DeCoursey, P.J. (Eds.), 2004. Chronobiology. Sinauer Associates Inc., Sunderland.

Flatt, T., Heyland, A. (Eds.), 2011. Mechanisms of Life History Evolution. Oxford University Press, Oxford.

Flatt, T., Tu, M.P., Tatar, M., 2005. Hormonal pleiotropy and the juvenile hormone regulation of Drosophila development and life history. Bioessays 27, 999-1010.

Goodman, W.G., Cousson, M., 2012. The juvenile hormones. In: Gilbert, L.I. (Ed.), Insect Endocrinology. Elsevier, The Netherlands, pp. 310-365.

Goodspeed, D., Chehab, E.W., Min-Venditti, A., Braam, J., Covington, M.F., 2012. Aradidopsis synthronizes jasmonate-mediated defense with insect circadian behavior. Proc. Natl. Acad. Sci. U.S.A. 109, 4674-4677.

Guerra, P.A., 2011. Evaluating the life history trade-off between dispersal and reproduction in wing dimorphic insects: a meta-analysis. Biol. Rev. 86, 813-835.

Hardie, J., Lees, A.D., 1985. Endocrine control of polymorphism and polyphenism. In: Kerkut, G.A., Gilbert, L.I. (Eds.), Comprehensive Insect Physiology, Biochemistry and Pharmacology. Pergamon Press, New York, pp. 441-49o. 
Harrison, R.G., 1980. Dispersal polymorphisms in insects. Annu. Rev. Ecol. Syst. 11, 95-118.

Harshman, L.G., Zera, A.J., 2007. The cost of reproduction. Trends Ecol. Evol. 22, 80-86. Hemond, E., Vollmer, S.V., 2015. Diurnal and nocturnal transcriptomic variation in the Caribbean staghorn coral, Acropora cervicornis. Mol. Ecol. 24, 4460-4473.

Issac, R.E., Ekbote, U., Coates, D., Shirras, A.D., 1999. Insect angiotensin-converting enzyme. A processing enzyme with broad substrate specificity. New York Acad. Sci. 897, 342-347.

Issac, R.E., Lamango, N.S., Ekbote, U., Taylor, C.A., Hurst, D., et al., 2007. Angiotensin-converting enzyme as a target for the development of novel insect growth regulators. Peptides 28, 153-162.

Jindra, M., Palli, S.R., Riddiford, L.M., 2013. The juvenile hormone signaling pathway in insect development. Annu. Rev. Entomol. 58, 181-204.

Jones, C.M., Papanicolaou, A., Mironidis, G.K., Vontas, J., Yang, Y., et al., 2015. Genome-wide transcriptional signatures of migratory flight activity in a globally invasive insect pest. Mol. Ecol. 24, 4901-4911.

Kvist, J., Mattila, A., Somervuo, P., Ahola, V., Koskinen, P., et al., 2015. Flight-induced changes in gene expression in the Glanville fritillary butterfly. Mol. Ecol. 24, 4886-490o.

Livak, K.J., Schmittgen, T.D., 2001. Analysis of relative gene expression data using real-time quantitative PCR and the 2(-Delta Delta CT)) method. Methods 25, 402-408.

Love, M.I., Huber, W., Anders, S., 2014. Moderated estimation of fold change and dispersion for RNA-Seq data with DESeq2. Genome Biol. 15, 550.

Nijhout, H.F., 1994. Insect Hormones. Princeton University Press, Princeton.

Nijhout, H.F., Callier, V., 2013. A new mathematical approach for qualitatively modeling the insulin-TOR-MAPK network. Front. Physiol. 4, 45-53.

Pener, M.P., 1985. Hormonal effects on flight and migration. In: Kerkut, G.A., Gilbert, L.I. (Eds.), Comprehensive Insect Physiology, Biochemistry and Pharmacology. Pergamon Press, New York, pp. 441-550.

Pilkis, S.J., Claus, T.H., Kurland, I.J., Lange, A.J., 1995. 6-phosphofructo-2-kinase/ fructose-2,6-bisphosphatase: a metabolic signaling enzyme. Annu. Rev. Biochem. 64, 799-835.

Rankin, M.A., 1978. Hormonal control of migratory flight. In: Dingle, H. (Ed.), The Evolution of Insect Migration and Diapause. Springer, New York, pp. 139-163.

Rankin, M.A., Burchsted, J.C.A., 1992. The cost of migration in insects. Annu. Rev. Ecol. Syst. 37, 533-559.

Roff, D.A., 1986. The evolution of wing dimorphism in insects. Evolution 40, 1009-1020.

Savolainen, O., Lascoux, M., Merila, J., 2013. Ecological genomics of local adaptation. Nat. Rev./Genetics 14, 807-820.

Shang, F., Ding, B.-Y., et al., 2016. Differential expression of genes in the alate and apterous morphs of the brown citrus aphid, Toxoptera citricida. Sci. Rep. 6 , 32099. 
Sim, C., Denlinger, D., 2013. Insulin signaling and the regulation of insect diapause. Front. Physiol. 4, 1-10.

St-Cyr, J., Derome, N., Bernatchez, L., 2008. The transcriptomics of life history trade-offs in whitefish species pairs (Coregonus sp.). Mol. Ecol. 17, 1850-1870. Stearns, S.C., 1992. The Evolution of Life Histories. Oxford University Press, Oxford.

Taniguchi, C., Emanuelli, B., Kahn, C.R., 2006. Critical nodes in signaling pathways: insights into insulin action. Nat. Rev. Mol. Cell Biol. 7, 85-96.

Tatar, M., Kopelman, A., Epstein, D., Tu, M.-P., Yin, C.-M., et al., 2001. A mutant Drosophila insulin homolog that extends life-span and impairs neuroendocrine function. Science 292, 107-110.

Tu, M.P., Yin, C.M., Tatar, M., 2005. Mutations in insulin signaling pathway alter juvenile hormone synthesis in Drosophila melanogaster. Gen. Comp. Endocrinol. 142, 347-356.

Untergasser, A., Nijveen, H., Rao, X., Bisseling, T., Geurts, R., et al., 2007. Primer3Plus, an enhanced web interface to Primer3. Nucl. Acids Res. 35, 402-408.

Vellichirammal, N.N., Zera, A.J., Schilder, R.J., Wehrkamp, C., Riethoven, J.-J.M., Brisson, J.A., 2014. De novo transcriptome assembly from fat body and flight muscle transcripts to identify morph-specific gene expression in Gryllus firmus. PLOS ONE 9, e82129.

Walker, T.J., 1986. Monitoring the flights of field crickets (Gryllus spp) and a tachinid fly (Euphasiopteryx ochracea) in northern Florida. Fla. Entomol. 69, 678-685.

Wheat, C.W., Fescemyer, H.W., Kvist, J., Tas, E., Vera, J.C., et al., 2011. Functional genomics of life history variation in a butterfly metapopulation. Mol. Ecol. 20, $1813-1828$.

Wilson, R., Changwei, C., Ratcliffe, N.A., 1999. Innate immunity in insects: the role of multiple, endogenous serum lectins in the recognition of foreign invaders in the cockroach, Blaberus discoidalis. J. Immunity 162, 1590-1596.

Wu, Q., Brown, M., 2006. Signaling and function of insulin-like peptides in insects. Annu. Rev. Entomol. 51, 1-24.

Xue, H.-J., Xue, J., et al., 2015. Two insulin receptors determine alternate wing morphs in planthoppers. Nature 519, 464-467.

Yang, X., Liu, X., Xu, X., Li, Z., Li, Y., et al., 2014. Gene expression profiling in winged and wingless cotton aphids, Aphis gossypii (Hemiptera: Aphidae). Intl. J. Bio. Sci. 10, 257-267.

Zera, A.J., 2005. Intermediary metabolism and life history trade-offs: lipid metabolism in lines of the wing-polymorphic cricket, Gryllus firmus, selected for flight capability vs. early age reproduction. Integr. Comp. Biol. 45, 511-524.

Zera, A.J., 2016. Evolutionary endocrinology of hormonal rhythms: JH titer circadian polymorphism in Gryllus firmus. Integr. Comp. Biol. 56, 159-170.

Zera, A.J., Bottsford, J., 2001. The endocrine-genetic basis of life history variation: Relationship between the ecdysteroid titer and morph-specific reproduction in the wing-polymorphic cricket, Gryllus firmus. Evolution 55, 538-549. 
Zera, A.J., Brisson, J.A., 2012. Quantitative, physiological, and molecular genetics of dispersal and migration. In: Colbert, J., Baguette, M., Benton, T.G., Bullock, J.M. (Eds.), Dispersal Ecology and Evolution. Oxford University Press, Oxford, pp. 63-82.

Zera, A.J., Denno, R.F., 1997. Physiology and ecology of dispersal polymorphism in insects. Annu. Rev. Entomol. 42, 207-231.

Zera, A.J., Harshman, L.G., 2001. Physiology of life-history trade-offs in animals. Annu. Rev. Ecol. Syst. 32, 95-106.

Zera, A.J., Harshman, L.G., 2009. Laboratory selection studies of life-history physiology in insects. In: Garland, T., Rose, M.R. (Eds.), Experimental evolution: Methods and Applications. University of California Press, Berkeley, pp. 217-262.

Zera, A.J., Harshman, L.G., 2011. Intermediary metabolism and the biochemicalmolecular basis of life history variation and trade-offs in two insect models. In: Flatt, T., Heyland, A. (Eds.), Mechanisms of Life History Evolution. Oxford University Press,, Oxford, pp. 311-328.

Zera, A.J., Larsen, A., 2001. The metabolic basis of life history variation: genetic and phenotypic differences in lipid reserves among life history morphs of the wing-polymorphic cricket, Gryllus firmus. J. Insect Physiol. 47, 1147-116o.

Zera, A.J., Sall, J., Grudzinski, K., 1997. Flight-muscle polymorphism in the cricket Gryllus firmus: muscle characteristics and their influence on the evolution of flightlessness. Physiol. Zool. 70, 519-529.

Zera, A.J., Vellichirammal, N.N., Brisson, J.A., 2017. Hormonal circadian rhythms in the wing-polymorphic cricket Gryllus: integrating chronobiology, endocrinology and evolution. In: Horch, H.W., Mito, T., Popadić, A., Ohuchi, H., Noji, S. (Eds.), Crickets as a Model Organism: Development, Regeneration, and Behavior. Springer, Berlin, pp. 91-103.

Zera, A.J., Zhao, Z., 2003. Life history evolution and the microevolution of intermediary metabolism: activities of lipid-metabolizing enzymes in life-history morphs of a wing-dimorphic cricket. Evolution 57, 568-596.

Zera, A.J., Zhao, Z., 2006. Intermediary metabolism and life history trade-offs: differential metabolism of amino acids underlies the dispersal-reproduction trade-off in a wing-polymorphic cricket. Am. Nat. 16, 889-9oo.

Zera, A.J., Zhao, Z., 2009. Morph-associated JH titer diel rhythm in Gryllus firmus: experimental verification of its circadian basis and cycle characterization in artifically-selected lines raised in the field. J. Insect Physiol. 55, 450-458.

Zera, A.J., Zhao, Z., Kaliseck, K., 2007. Hormones in the field: Evolutionary endocrinology of juvenile hormone and ecdysteroids in field populations of the wing-dimorphic cricket Gryllus firmus. Physiol. Biochem. Zool. 80, 592-6o6.

Zhao, Z., Zera, A.J., 2002. Differential lipid biosynthesis underlies a tradeoff between reproduction and flight capability in a wing-polymorphic cricket. Proc. Natl. Acad. Sci. U.S.A. 99, 16829-16834.

Zhao, Z., Zera, A.J., 2004. The hemolymph JH titer exhibits a large-amplitude, morph-dependent, diurnal cycle in the wing-polymorphic cricket, Gryllus firmus. J. Insect Physiol. 50, 93-102. 